\title{
and \\ COVID-19's Impact on Higher Education: A Rapid Review of Early Reactive Literature
}

\author{
Muzammal Ahmad Khan
}

Citation: Khan, M.A. COVID-19's Impact on Higher Education: A Rapid Review of Early Reactive Literature. Educ. Sci. 2021, 11, 421. https://doi.org/10.3390/ educsci11080421

Academic Editor: Rabindra Nepal

Received: 26 June 2021

Accepted: 28 July 2021

Published: 11 August 2021

Publisher's Note: MDPI stays neutral with regard to jurisdictional claims in published maps and institutional affiliations.

Copyright: (C) 2021 by the author. Licensee MDPI, Basel, Switzerland. This article is an open access article distributed under the terms and conditions of the Creative Commons Attribution (CC BY) license (https:// creativecommons.org/licenses/by/ $4.0 /)$.
School of Business and Creative Industries Paisley Campus, University of the West of Scotland, High Street, Paisley PA12BE, UK; muzammal.khan@uws.ac.uk

\begin{abstract}
This rapid systematic review aims to examine emerging evidence on the effects of COVID19 on educational institutions and assess the prevalence of e-learning changes in the sector. This paper reviews literature on learning, teaching, and assessment approaches adopted since the COVID-19 outbreak, and assesses the impact on the sector, staff, and students, summarizing findings from peer-reviewed articles. It categorizes these into five key themes: (1) digital learning, (2) e-learning challenges, (3) digital transition to emergency virtual assessment (EVA), (4) psychological impact of COVID-19, and (5) creating collaborative cultures. This represents the first systematic review of COVID-19's impact on education, clarifying current themes being investigated. The author suggests that the term 'emergency virtual assessment' (EVA) is now added for future research discussion. Finally, the paper identifies research gaps, including researching the impact on lesser developed countries, the psychological impact of transition, and the important role of leadership and leadership styles during the transition and handling of the pandemic.
\end{abstract}

Keywords: COVID-19; review; e-learning; education transition; collaboration

\section{Introduction}

On 11 March 2020, the World Health Organization (WHO) changed the classification of the novel infection COVID-19 from an epidemic to a pandemic. COVID-19 is a respiratory infection that can range from mild symptoms to moderate to severe illness. Due to the incredibly contagious nature of this virus, it quickly spread across the world and created population density-compliant hotspots (e.g., New York City) [1]. COVID-19 travels by saliva particles or respiratory secretions when an infected individual coughs or sneezes [2], with current evidence indicating that the main means of spreading the infection is through small droplets which are released whilst talking [3]. Microdroplets can remain stagnant in the air for up to $20 \mathrm{~min}$, so keeping a safe distance from others, using proper masks, and improving air circulation helps to minimize the risk of infection [4]. Most individuals have mild to moderate symptoms and recover without medical intervention, but older individuals, and those with underlying diseases, such as diabetes and cancer, appear to be more likely to develop a severe illness [5]. In reaction to the virus's fast spread, population quarantine has been introduced by governments across the world to assist nations in their attempts to mitigate adverse effects of COVID-19 [6].

The COVID-19 crisis has affected education adversely, both here in the United Kingdom and across the globe, with classes and assessments being delayed or cancelled due to the lockdown. Most colleges and universities have also had to grapple with the challenges of virtual learning [7], many having to rapidly move from face-to-face traditional teaching methods to hitherto uncharted territories. Education institutions have been encouraged to develop pandemic management strategies in order to promote continued learning among students. For example, the UK government advised people to "limit social contact as much as you can" and went on to state that "you can still work but we are asking as many as possible to work from home" [8] (no pagination). This was followed by the postponement of face-to-face teaching for education sectors around the world, with educators advised to 
provide alternative activities as replacements for attendance at lectures, tutorials, seminars, laboratories, and workshops. A study uses the term "emergency remote teaching" (ERT) to describe the impact on the delivery of education [9] (p. 471). The author of this paper will extend this definition to include the term emergency virtual assessment (EVA), particularly relevant as educational institutions have been required, at the eleventh hour, to completely overhaul their planned assessment processes. As the crisis has developed, the rapidly changing nature of communication provided to students and academics may have added additional sources of pressure and anxiety. Psychological and emotional influences have been apparent since the start of the COVID-19 pandemic. Its advent, and spread, has caused a great deal of concern to people who were already living with an elevated degree of anxiety [10].

Research and case studies focusing on COVID-19's impact on educational institutions and predicting post-COVID-19 developments in the education sector have already been published in major international scientific journals, particularly in relation to educational institutions, with publications from China, the United Kingdom, the United States, and various other countries. Several of these reports have already started to address the questions, such as how technology is transforming remote learning, what the likely outcomes will be and what change they will bring over time, the likely impact of COVID-19 on the educational institutional marketplace, and clinical and post-lockdown perspectives for individual educational institutions. However, a review of the early published literature immediately following the start of the pandemic that consolidates what has been learned from each study is currently missing. This current extraordinary crises' influence on educational institutions has yet to be determined fully to understand the early interventions that were put in place to transform e-learning to cope with the impact of the pandemic. This rapid review therefore aims to examine emerging evidence on the effects of COVID-19 on educational institutions and to assess the prevalence of e-learning changes in the sector. The World Health Organization advocates for rapid reviews to be carried out in order to obtain appropriate explanations of such challenges [11]. To achieve the above aim, the following objectives have been established for this review: (1) to summarize the impact of COVID-19 as reported in currently available studies on educational institutions; (2) to investigate the measures which were put in place following the lockdown of educational institutions; and (3) to assess gaps in knowledge and understanding and identify possible future research directions relating to the impact on education of COVID-19. In addition, this review offers recommendations to educators and education establishments about how they may prepare for the move from traditional education to an online digital world. The structure of this article is as follows: the next section provides an overview of the methods adopted for this study, and is followed by the descriptive results, the themes identified from the literature, and finally, the conclusions and future research recommendations.

\section{Search Method}

A rapid review methodology was used to bring together evidence [11]. A systematic search of literature published from 1 March 2020 to 10 July 2020 was carried out using electronic databases. The articles were gathered from sources that have a significant number of research articles, particularly relating to educational institutions. Science Direct, Emerald, Pro-quest, Wiley Online Library, JStore, Sage Publications, Springer Link, and Taylor \& Francis were among the publishers that were targeted. The use of larger databases was considered in order to increase the sample's representativeness. [12]. These databases, which cover nations from all over the world, are regarded valuable for academics and practitioners looking for current evidence on the phenomena under investigation. Google Scholar was utilized to double-check the search and find any relevant studies that were missed during the original database search [13]. Keyword searches in chosen databases are the most common search strategies [14,15].

The search was based on keywords taken from Google Scholar's basic search. The keyword search used terms including COVID-19 and education, higher education or 
university education, COVID-19 pandemic or quarantine and education, coronavirus disease-19 college education or school education, Wuhan coronavirus and 2019-nCoV, and novel coronavirus SARS-CoV; these were searched for within the title, abstract, and keyword sections, a technique used in previous research [16]. These keywords were used regularly to ensure that no relevant articles were overlooked, and they were occasionally combined using the advanced search option [17]. This author used Boolean operators (and, or) to increase the combined multiple search terms and the overall efficacy of the search range. This is an approach used by several reviewed articles [18-20]. The benefit of using Boolean operators is that it allows, in some instances, access to a wider range of resources than a single search would permit, particularly where similar but differing terms are used for the same topic, and in other instances allows the searches to be narrowed, making it easier for the researcher to find a more direct and relevant source [21]. The Boolean operator "not" was considered unnecessary for the purpose of this paper. The searches were concluded on 10 July 2020, and two independent assessors then evaluated the search results [22]. This review used independent assessors who were able to separately verify the relevant data allowed the researcher to confirm the authenticity and validity of the data and provide confidence that it could be applied without fear of inconsistencies, inaccuracies, or repetition. Many research articles were discovered by browsing internet databases [12].

The initial search strategy's results were then filtered by title and abstract, this strategy having already been used by previous researchers [23]. The entire texts of relevant publications were reviewed for inclusion and exclusion, with the criteria for inclusion and exclusion outlined below in Table 1.

Table 1. Inclusion and exclusion criteria (source: compiled by author).

(a) Must involve COVID-19 and education as a main topic of research.

(b) The article must discuss COVID-19's impact on the ways in which it may have impacted any educational establishment, e.g., HE, college, school, as the primary component; the article may have been published anywhere in the world

(c) Pre-printed articles are included. (a) Editorials, commentaries, letters to editors, news articles, and opinions are excluded.

(b) Articles that discuss education settings only but which do not explain any link with COVID-19 are excluded.

(c) Studies dealing with other viruses.

(d) Studies in other languages with no English translation.

In this review, only peer-reviewed studies that investigated COVID-19's impact on institutions in any educational sector were included for analysis. Selected studies that were not written in the English language, or translated into English, were excluded.

During the search process, 118 articles related to COVID-19 and general education were extracted from the databases during the period. During the screening process, 42 articles relating to non-higher education were dismissed, leaving only 76 eligible articles that were about both COVID-19 and higher education. Four of these articles were then excluded due to duplication. A further 33 articles were deleted because they did not fully meet the inclusion and exclusion criteria set out in Table 1 . These included review papers, opinion pieces, editorials, and letters that did not offer original data, as well as studies that reported instances with insufficient information. Having reviewed only the title and abstract section of papers for selection purposes, the researcher then read the full texts for analysis purposes.

\section{Descriptive Results}

This review identified 39 studies that focused on the impact of the COVID-19 pandemic on educational institutions. This section presents descriptive results in order to quantify the research whilst focusing on a geographic focus, and the methods used when conducting the research into this new phenomenon. 


\subsection{Geographic Regions Studied}

The research found that most studies to date were published on educational institutions in the USA, again likely as a result of the request for special issues (see Figure 1). This pandemic is new, and it is expected that research on COVID-19 will increase in future and will concentrate on the impact on specific countries. This could be a positive step in promoting research on topics specific to regions that are most affected by the COVID-19 outbreak. Figure 1 shows the spread of research output that concentrated primarily on specific countries. If special issues continue to target countries such as Brazil, India, Mexico, and Iran in order to observe, understand and improve the quality of the shift towards online learning and identify better strategies for dealing with the new education required to support learners, they may widen the scope of the country profiles being investigated. Some of these are developing nations and have different cultural, economic, and social profiles to that of the developed nations which seem to deal with pandemics and radical changes in educational institutions more effectively. Research that focusses on poorer, as well as developing countries, can alleviate tensions by highlighting areas for improvement and recommending best practices to support educators and educational institutions in these countries.

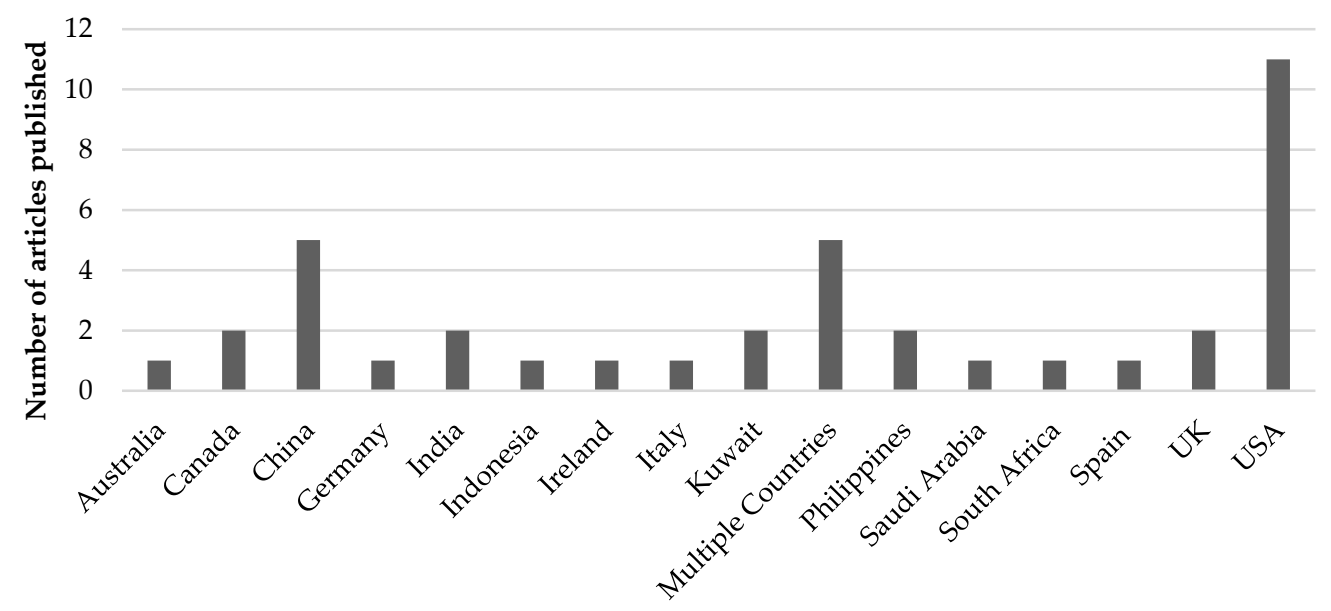

Figure 1. Geographic coverage of literature so far (source: compiled by author).

Research issues must be discovered all around the world, regardless of a country's standing since this may give a different discussion and context to the argument on COVID19 's influence on educational institutions. Scholarly conferences (online), journal special issues, and research partnerships among academics from other nations might broaden the field of study in underdeveloped and undeveloped countries. Local researchers can every so often enhance the level of investigation in their home country, as can researchers who are based outside their home countries. It is recommended that these scholars debate changes in educational institutions due to the pandemic and observe how these educational institutions might better prepare to tackle future outbreaks/pandemics.

\subsection{General Methods That Have Been Used}

Figure 2 shows the recent focus that has been used when examining the influence of COVID-19 on educational institutions. Many of these studies, perhaps as a direct consequence of the lockdown, were conducted using online questionnaires targeted mostly at students and staff. Document analyses have been the most consistently used research methods where researchers have relied on content such as module performance questionnaires, student feedback, course content, university correspondence, and official documents. These examine the impacts but also make relevant suggestions on how educational institutions can move to fully online learning (e-learning). Documentary analysis provides researchers with easy access to data, and based on such analysis, presents measures that can support 
educational institutions' future strategies and learning during and after the pandemic. Although documentary (secondary sources) analysis may provide quick findings, this might not be as in-depth as other methods, such as interviews and focus groups, that provide richer and more detailed information about the subject being investigated. In addition, it is difficult to ascertain the generality of these studies that were included in the review, as documentary analysis on its own might not produce generalized results. There is a pressing need to broaden the geographic reach of COVID-19 and education research, as well as its methodological approaches. The perspectives of key stakeholders should be ascertained using qualitative approaches [15].

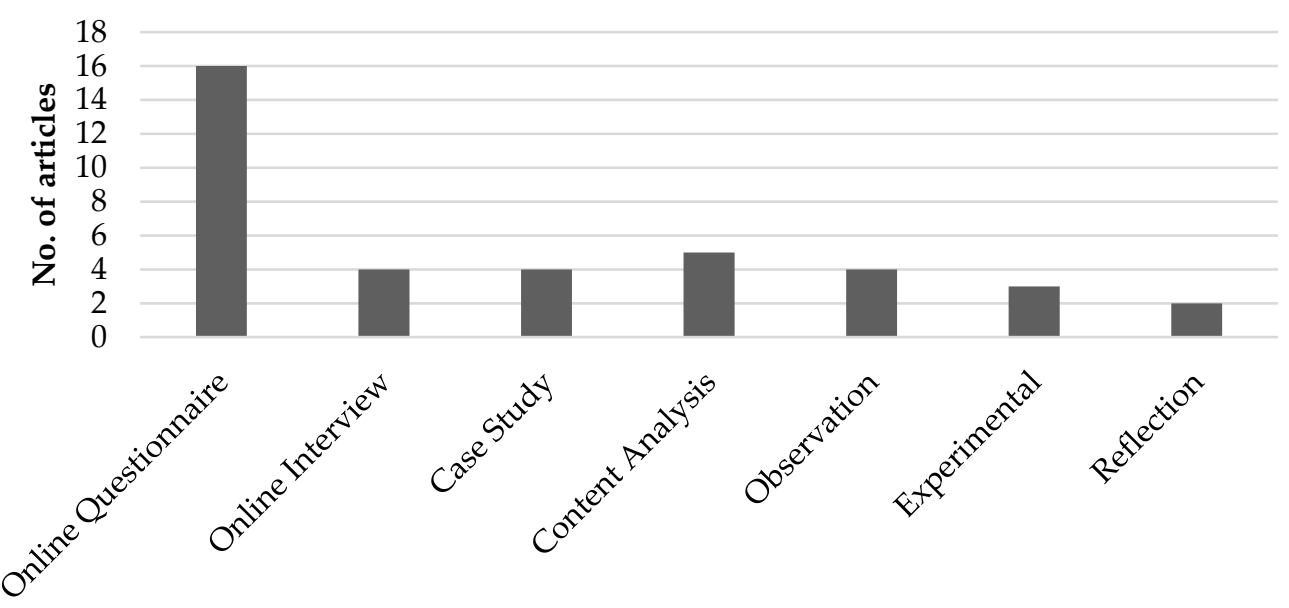

Research Methods

Figure 2. Methods used in publications (source: compiled by author).

Future studies could analyze institutional leadership communication to staff and students before, during, and after the lockdown. This could be based on communication methods such as social media and website communications. These studies could help the leadership of universities and other educational institutions to better plan and execute effective communication. Unclear communication can increase anxiety and stress among staff and students, as well as students' parents and families, during crisis events. Without this documentary analysis, it may not be possible to fully understand the issues, and it may lead to limited evidence being gathered and incomplete results being obtained. Any further analysis of the impact of COVID-19 may be better assessed using in-depth online questionnaires and interviews which could help improve understanding of how education can move from the traditional learning approaches to online learning. Finally, future researchers may consider the use of a mixed method approach to allow a more rigorous analysis of such issues as COVID-19 and how it has brought radical changes in academia and wider society. It is crucial to note that the goal of this study is not to support one approach over another; rather, it is to raise educated questions regarding COVID-19 and its influence on educational institutions.

\section{Thematic Analysis}

During the review process, several themes began to appear, and it seems appropriate to break these themes down into the following key areas namely digital learning, E-learning challenges, the digital transition to emergency virtual assessment (EVA), the psychological impact of COVID-19, and creating collaborative cultures. This thematic analysis will now discuss the key findings that emerged within each of these identified themes. 


\subsection{Digital Learning}

In line with many other publications, a study [24] highlights that COVID-19 has compelled institutions to pursue virtual/online education. In response to this, most studies examined the adoption/emergence of digital learning and its impact on educational institutions after the announcement of the pandemic in January/February. Six of these papers show that digital learning has a beneficial influence. Staff technical skills, for example, have increased as a result of digital learning [25]; education systems have been better restructured [26]; courses have been rapidly transformed [27]; because of advancements in technology and the virtual environment, there has been a rise in multifaceted e-learning techniques [28]; there have been better opportunities to provide feedback to students [29]; and there has also been progress in the fields of information technology literature, digital creativity, digital research, digital identity management, and students' digital competences connected to experiences that are also relevant to ordinary digital life [30]. Students who believe themselves to have high levels of digital competence in their everyday lives are more likely to perceive themselves to have high levels of digital competence in their educational lives.

However, other studies indicate a detrimental influence from this shift in schooling to digital learning. Staff and students, for example, were compelled to fully migrate to virtual learning in a relatively short period of time [24] and students with diverse learning requirements had just this one option as a learning choice [31]; in addition, there was a lack of student-teacher contact, which often resulted in poor teaching results, with some teachers simply duplicating existing content and moving it online without following any subjective direction. One study raises several issues concerning the transition to ERT, such as: (1) the move to ERT affecting instructors' capacity to facilitate skills development activities; (2) unfair access to learning tools, materials, and resources impacting upon certain students' motivation and engagements; (3) several teachers raising concerns over the overall efficacy of online techniques; and (4) numerous doubts being expressed about the future viability of education institutions if only online platforms provide post-pandemic education [32]. Another study highlights students in China perceiving there to be high online learning participation costs, particularly from the high costs of purchasing internet data time for an online learning experience [33]. Finally, one researcher identified that students who were educated using an online learning management system participated less in the learning process [34]. The rapid spread of COVID-19 forced educational institutions across the world to change many of their educational practices at a hitherto unprecedented speed and clearly the influence has been regarded quite differently by the authors mentioned above, with some welcoming the shift and seeing the benefits it will bring to educational institutions in the future, and others being more cautious or even negative. Interestingly, the most negative feedback comes from Chinese perspectives and perhaps suggests an educational culture that is not yet attuned to online learning.

\subsection{E-Learning Challenges}

Some studies have pointed out the challenges that have been faced by educational institutions, particularly by educators. For example, one study highlights several categories that were impacted by the COVID-19 pandemic and the changes that followed. Change management challenges, e-learning system technical issues, financial assistance issues, technology factors, e-learning quality system factors, cultural factors, self-efficiency elements, and trust factors are among those emphasized [35]. Although this study was conducted entirely in Jordan, these are categories that can be attributed to educational institutions across cultural divides, regardless of whether the countries affected are developed, developing, or economically poor. Similarly, another researcher highlights categories that have an influence on educational institutions and explicitly refers to some bad and some good outcomes. Time constraints, changes in assessment (EVA), and consequences for student involvement and relationships were among the drawbacks. Positive outcomes included the possibility of developing new resources and fostering academic collabora- 
tion [36]. Some authors concentrate on the impact on the student body and on student ability to deal with online learning, in place of face-to-face teaching. This appears to have increased the already-existing disparities faced by impoverished populations across the world [28]. Another researcher emphasizes the challenges faced by students and faculties owing to their inability to use online learning systems [37], whilst another study shows that not only do some students lack competence, but some lack self-control when face-to-face instruction is not accessible [31]. They imply that the total independent learning effect is unsatisfactory. One study finds that internet connectivity is very poor in China and, for many of the international students studying at universities in China, this left them with no other option but to remain in their student dormitories so that they could access their university's internet services [33].

In common with the previous section on the impact of digital learning, it appears that the jury remains both unconvinced and undecided on the effectiveness of online learning, particularly when it is imposed on educational institutions and their students. However, a study suggests that it is 'impossible to suddenly become an expert in online teaching and learning' ([25] p. 303). Educational institutions and students appear to be at the bottom of a very steep learning curve. Research will very certainly continue to produce contradictory and confirming evidence of excellent, poor, and indifferent behavior, giving researchers and practitioners something to think about and discuss.

\subsection{Digital Transition to Emergency Virtual Assessment (EVA)}

Transitions to remote learning have featured widely within the literature on COVID-19 and its impact on educational institutions. The findings and recommendations by authors who have discussed this issue have tended to concentrate on three areas, which the researcher will here refer to pedagogical, methodological, and tactical. Firstly, referring to the articles that predominantly focus on pedagogy, authors such as $[38,39]$ stress the importance of adopting strategies for designing online courses that make building relationships between educators and learners more effective, whilst continuing to meet the goals of the curriculum. In addition, they suggest that any such adoption should allow a shared understanding of research, and the use of approaches in education that ensure rapid access and accurate dissemination of resources, all of which must be "pedagogically sound". One study suggests that a pedagogical approach that may help to improve the ability of teachers to design and facilitate e-learning could be to adopt a heutagogical approach, one where learning is self-determined and which puts the students, not the teacher, at the center of the learning experience [24]. This is something that, in principle, should be relevant to online learning methods. Another study also identifies pedagogical issues and concentrates on how emergency remote teaching (ERT) can focus on the current inequities within teaching and help to ensure educational justice [40], whereas another study suggests that the existing curriculum is somewhat obsolete and requires a shake-up, which bimodal education and the updating of digital competencies may bring [41].

Secondly, authors who propose methodological approaches specify that the importance of identifying technical difficulties, considering how these may be resolved in advance, and the importance of always having a plan B [42]. A part can be played by cloud technology [31], one author stressing the importance of contingency planning for such factors as traffic overload on online platforms [43]. This article also makes it clear that there is an important requirement to ensure that teaching content is matched by academics' readiness to adapt to change, and that students are clear on what is required in terms of online learning behavior. Finally, a study suggests that teachers should be encouraged to use flipped classroom approaches, and that universities should become adept at setting policies in relation to these approaches [44].

\subsection{Psychological Impact of COVID-19}

Mental health issues feature prominently in a few of the articles sampled in this review. Some were concerned that the move to online learning has had a negative impact on both 
staff and students' mental health. An early study highlights that college students displayed significant mental health issues when faced with a public health emergency [45]. A very important finding comes from a study of the online migration that followed COVID-19 that highlights the severe damage caused to pedagogical roles within higher education, in terms of dysfunction and disturbance, not only from an educational perspective but also in terms of academics' personal lives [46]. They also note that online migration of learning creates additional challenges in other areas of academic life, particularly in terms of the academic labor market, and the impact on the pattern of student recruitment, not to mention the local economies that rely on educational institutions. There should be a concerted effort to find a means of tackling the issues identified and recognition that innovative and helpful approaches are needed to address mental health issues, not only for students but also for academics, by engaging in activities that assist in alleviating anxieties caused by the stoppage of 'normal' academic activity [46].

Clearly any changes are challenging. However, change coupled with a serious global pandemic is unprecedented. The abrupt closure of educational institutions, followed by a lockdown, has left people bewildered and dealing with a variety of difficulties that can contribute to increased anxiety and stress, such as job instability, financial concerns, home schooling, despair, loneliness, loss, trauma, and sickness. To add to this, a complete change in educational delivery and assessment (EVA) where internet technology, software, and change of assessment technique has required rapid and often difficult adaptation. It is easy to forget that there are two parties involved, one being the educational provider and the other the educational recipient. The first, the provider, who is challenged to completely redesign their teaching assessment methods (EVA), may often forget the impact that this can have on the educational recipient. The second, the receiver, who may be overwhelmed by the pace of change and its impact on their personal life, may not always recognize the strain imposed on educational providers. Both need to understand each other's viewpoints. Empathy is essential, and mutual empathy is key to ensuring that any future such shocks are managed efficiently and effectively; at the heart of this is clear and detailed communication [47]. The pandemic's influence on mental health has been significant, although the evidence is less clear in the literature reviewed. This necessitates significant future study efforts to investigate the impact on all parties involved.

\subsection{Creating Collaborative Cultures}

Changes in teaching delivery have required people to collaborate at different levels in educational institutions. Several papers observe that good collaborative culture can often be recognized by traits such as clear and flexible structures, prioritization of tasks, hard work, and communication within the professional communities, and must rely on goodwill $[7,48]$. Other authors $[49,50]$ suggest that the means of achieving a good collaborative culture may be to ensure that a university establishes itself as a community service and does so with a view to finding new income streams, responding to cultural shifts, and establishing clear opportunities for academics at all levels within academia to collaborate at, and with, higher levels within the industry. Studies provide an important view about collaboration, suggesting that carefully designed online collaborative learning might be an extremely worthwhile method for students to interact with their peers and offer an influential vehicle for them to regulate their own and others' learning whilst honing skills collectively as a group [51]. Finally, some studies consider the future of education post-COVID-19 with a view to online delivery continuing within the education sector. One study suggests that the current situation could be a driving force towards the development of new and better technological resources, and closer collaboration between academics within schools and departments in individual universities and across the university sector [36]. Another study recommends that local communities form part of future educational decisions made within the communities in which they reside [9]. Furthermore, a study identifies that an academic has a pivotal role to play in developing sustainable and quality student support, and that student support networks are essential in ensuring that online delivery not only 
works but continues to provide successful output [52]. At the heart of collaboration there is an important place for regulators and funders of education, without whom the recent adaptation of teaching and learning would not have been possible, albeit the transition has not always been smooth. Some studies recognize the importance currently played by governments but also emphasize the important role that they will need to play in the future [53]. Governments should help to fund the transition to online learning, and there is still some considerable way to go before governments and other international organizations can fulfil their role in this regard [28]. There is a belief that there needs to be greater dialogue across the world between governments, that solutions are found to ensure that learning continues, and that potential and existing students do not lose out on the right to be educated. Reviewing these articles has emphasized the importance of the social contract between educational institutions, the communities in which they operate, and the stakeholders that they serve, and that, going forward, universities need to ensure that this pivotal contract is maintained through better dialogue and collaboration.

\section{Recommendations from Published Studies}

Several authors provide some tactical suggestions (set out in Table 2 below) for dealing with issues facing educators and students in meeting the current crisis facing education. The various suggestions made by the above authors provide several themed approaches to online delivery, some of which appear obvious, but also some provide novel and innovative methods that can, if applied, potentially improve both the delivery of online teaching and the experience of the learners. The rise of online teaching platforms, since the outbreak of COVID-19 and the subsequent lockdown, such as Microsoft Teams, Google Meets, and Google Classroom, has been increasing. So too has the ability of both university staff and students to adapt rapidly to these alternative online support facilities. This is also true of the success that these platforms have had in supporting everyday life for individuals and families. This has highlighted the adaptability of the human being to changing circumstances and surroundings. The next stage in educational development using technology will be fascinating and, as one study suggests, we may be about to move into an age of the algorithm as the professor. Much awaits educational practitioners and learners [50].

Table 2. Key teaching and learning related suggestions by published studies (source: compiled by author).

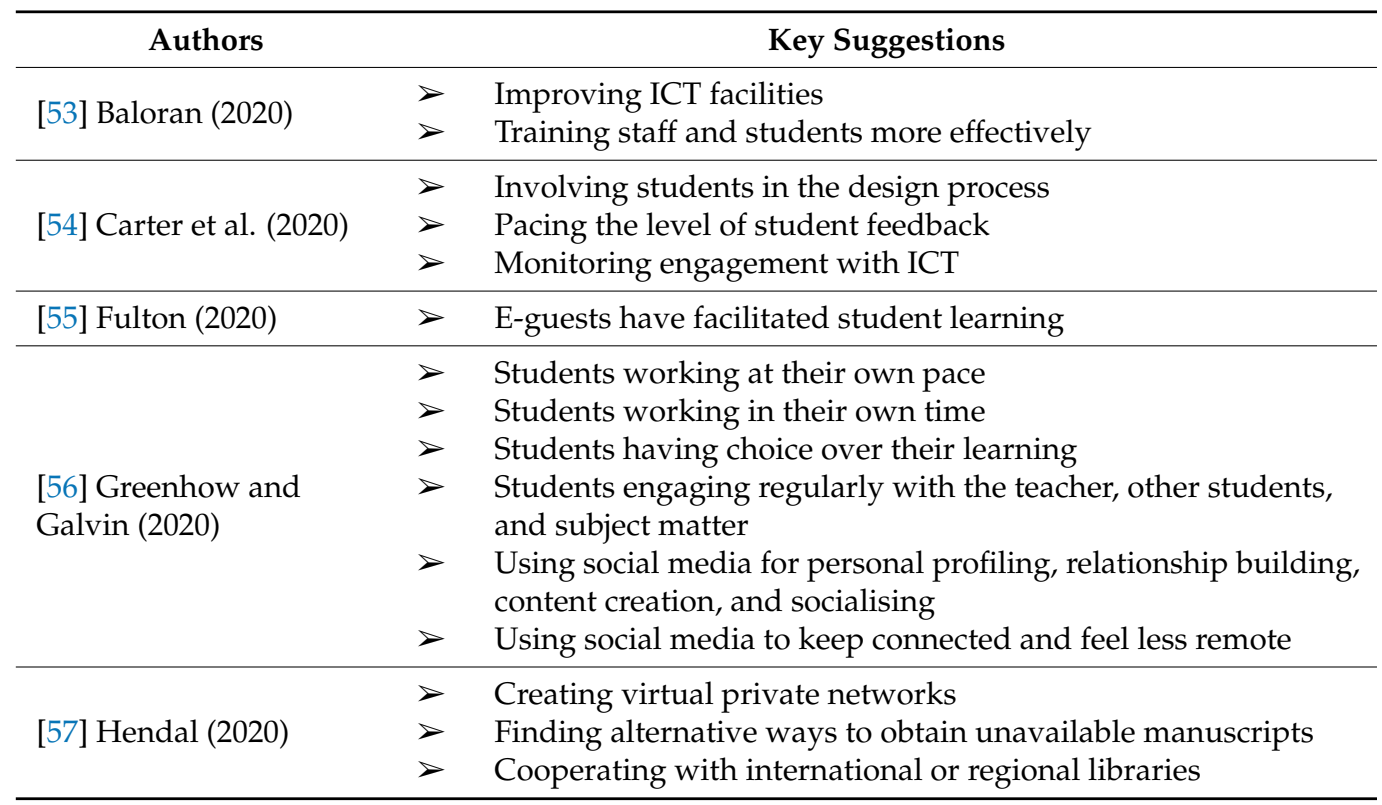


Table 2. Cont.

\begin{tabular}{lll}
\hline \multicolumn{1}{c}{ Authors } & & \multicolumn{1}{c}{ Key Suggestions } \\
\hline [49] Justis et al. (2020) & $>$ & $\begin{array}{l}\text { Encouraging educators to have shared goals in relation to } \\
\text { moving education online }\end{array}$ \\
& $>$ & Encouraging a participative culture \\
\hline [50] Krishnamurthy & $>$ & $\begin{array}{l}\text { Using a system of mentorship } \\
\text { Encouraging students to develop peer to peer learning }\end{array}$ \\
(2020) & $>$ & $\begin{array}{l}\text { Focusing more on value than on quality } \\
\text { Recognising the algorithm as a replacement for the professor }\end{array}$ \\
\hline [58] Mehta and Wang & $>$ & $\begin{array}{l}\text { Promoting inter-university collaboration on the provision of } \\
\text { digital services via libraries }\end{array}$ \\
(2020) & $>$ & $\begin{array}{l}\text { Using a standards-based modification of existing courses to } \\
\text { improve online learning experiences }\end{array}$ \\
\hline [59] Murillo and Jones & $>$ & $\begin{array}{l}\text { Paying attention to navigation, readability, and accessibility } \\
\text { during digital transformation of courses }\end{array}$ \\
(2020) & $>$ & $\begin{array}{l}\text { Transforming libraries and offering new visions for services } \\
\text { which focus on building new relationships within communities }\end{array}$ \\
\hline [60] Tammaro and & $>$ & $\begin{array}{l}\text { Flipping the classroom (online) } \\
\text { Ensuring educators introduce humour into online environment }\end{array}$ \\
Tammaro (2020) & $>$ & $\begin{array}{l}\text { Offering online live classrooms } \\
\text { Offering online on-demand teaching } \\
\text { Using video technology (also suggested by [43]) }\end{array}$ \\
\hline [44] Yen (2020) & $>$ &
\end{tabular}

\section{Conclusions}

Although current literature is still relatively scarce in relation to COVID-19's impact on educational institutions, there are indications of increased levels of disruption in teaching, especially in the migration from face-to-face teaching to online learning. Several studies have proposed ways in which such transitions might be achieved, for example, training in digital literacy, the use of online flipped classrooms, encouraging students to use peer to peer learning, and the building of community collaborations. Given that this pandemic has pressured teachers to go beyond their normal working routine, the reviewed literature has also shown the negative psychological impact of the pandemic. The evidence remains limited on the psychological impact of the pandemic on individuals working in education institutions and this calls for rigorous investigation of the issues on mental health among individuals in education. Finally, it is extremely important that the educators must focus on improving student engagement whether virtually or onsite, during the pandemic as well as post-pandemic [61].

\section{Strengths and Limitations of the Review}

This paper has several strengths that help to navigate the path of research into the impact of COVID-19 on education sectors around the world. Firstly, it provides a comprehensive overview of peer-reviewed literature published in journals through a systematic approach. Secondly, in using only peer-reviewed literature, rigor and validity are added to the approach and recommendations made for future research are shaped. Finally, by linking the key themes within the literature, the paper identifies new themes that again may feature as part of future research.

A key limitation of this review is one that has developed naturally due to the rapid growth of COVID-19. By necessity, the review findings have been limited to a three-month period. Secondly, only peer-reviewed articles published in respected journals have been included. Publications such as editorials, commentaries, periodicals, online discussions, and any other sources from grey literature have been excluded. Finally, the review found that most papers that were published have concentrated on specific countries. Only the 
USA, China, UK, India, Philippines, and Kuwait have featured in more than one paper, only the USA was included in ten or more papers, and of the remaining countries, only China featured in more than two. The findings of the review therefore cannot be generalized to countries where there has been no research published.

\section{Further Directions for Research}

Much of the research that has been included in this review has come from the developed or the stronger developing countries, with almost no research published in relation to lesser developed but developing countries, or to undeveloped countries, yet education is at the heart of all these countries' futures. How those countries have adapted to the COVID-19 crisis and how they have responded in terms of education is a key area of research still to be examined. It will be interesting to compare the experience of teachers, students, and other education stakeholders in these regions and/or countries.

Given that evidence suggests that people from Black, Asian, and Minority groups (BAME) are more likely to be seriously impacted by COVID-19, the emphasis in relation to education should focus directly on the impact on these groups and compare the damage done to the education of BAME students and staff. Other considerations may focus on, for example, the impact on employment, economic growth, future earning differentials, trade gaps, student recruitment, and digital literacy.

Some of the papers used for this review have identified psychological issues, such as stress and anxiety that changes brought by COVID-19 have introduced, or which have added to existing conditions. It is somewhat surprising that this has not featured more widely within the research carried out to date. This may indicate scope for future research in this area and the author suggests that such research may concentrate on the impact on students and academic staff, as well as support staff. Students, for example, in nursing programs, may be fascinating to research, given that many were also thrust into the front-line fight about COVID-19 at the height of the pandemic. Their experiences of changes, not only to their education but also to their front-line experience, may be worthy of investigation in terms of educational, personal, employment, and psychological impacts.

Research may also be worthwhile in comparing how various universities adapted to changes in assessment requirements (EVA) as the COVID-19 crisis developed. These changes are perhaps felt most directly by programs recognized by professional and statutory regulatory bodies (PSRBs), including Nursing and Midwifery, Dentistry, Medicine, Veterinary Medicine, Architecture, Law, HRM, Accountancy, Engineering and Management. These programs have required cooperation and permission of PSRBs where assessment strategies have changed to meet the challenges of online assessment (EVA). In some cases, some programs required the permission of multiple PSRBs and not all these PSRBs agreed on the strategies that should be adopted. Research in this area may help to unify approaches to alternative assessment across universities and help PSRBs to understand their impact on educational institutions and students, making any future crisis more manageable.

The role of leadership in handling the transformative change, leading in crisis, and structuring effective communication may also be worthy of research. Due to the difficulties of communicating during a rapidly evolving crisis where, by necessity, information must change as circumstances change, it may be interesting to hear the viewpoints of educational leadership and decision makers on how the crisis impacted their roles, and perhaps to contrast this with the views of teachers and students on how successful they viewed communications by leadership during this period.

The importance of hearing the student voice when decisions are being made in a time of crisis, pandemic, or radical change, may also be an important area to investigate. The speed of change brought by COVID-19 clearly did not make it easy to involve the student voice fully, but where decisions must be made without full consultation, the rationale for any decision must be communicated to students as soon as possible. Research in this area may perhaps investigate the level of input of the student voice during the decision-making 
process and immediately afterwards. It may also investigate why the student voice was not included.

One final suggestion for future research is to consider examining the post-COVID-19 impact on educational norms. Having introduced emergency remote teaching (ERT) and emergency remote assessment (ERA) at breakneck pace, what will future teaching norms look like? Will they continue to be remote, or will they revert to traditional teaching styles, or indeed, will we see blended or heutagogical approaches become the new norm? Will the 'emergency' in the terms ERT and ERA simply disappear and be replaced by remote teaching (RT) and remote assessment (RA). Research for this area is likely to require a longitudinal study.

Funding: This research received no external funding.

Institutional Review Board Statement: Not applicable.

Informed Consent Statement: Not applicable.

Conflicts of Interest: The authors declare no conflict of interest.

\section{References}

1. Intarasuwan, K.; Vazquez, J.; Shea, T.; Rajamani, M.; Price, B. Timeline: Tracking the Spread of COVID-19 in Tri-State. Available online: https:/ / www.nbcnewyork.com/news/local/timeline-tracking-the-spread-of-covid-19-in-tri-state/2313123/ (accessed on 12 July 2020).

2. Xu, R.; Cui, B.; Duan, X.; Zhang, P.; Zhou, X.; Yuan, Q. Saliva: Potential Diagnostic Value and Transmission of 2019-NCoV. Int. J. Oral Sci. 2020, 12, 11. [CrossRef]

3. Acter, T.; Uddin, N.; Das, J.; Akhter, A.; Choudhury, T.R.; Kim, S. Evolution of Severe Acute Respiratory Syndrome Coronavirus 2 (SARS-CoV-2) as Coronavirus Disease 2019 (COVID-19) Pandemic: A Global Health Emergency. Sci. Total Environ. 2020, 730. [CrossRef] [PubMed]

4. Kähler, C.J.; Hain, R. Fundamental Protective Mechanisms of Face Masks against Droplet Infections. J. Aerosol Sci. 2020, 148, 105617. [CrossRef] [PubMed]

5. Clark, A.; Jit, M.; Warren-Gash, C.; Guthrie, B.; Wang, H.H.X.; Mercer, S.W.; Sanderson, C.; McKee, M.; Troeger, C.; Ong, K.I.; et al. How Many Are at Increased Risk of Severe COVID-19 Disease? Rapid Global, Regional and National Estimates for 2020. medRxiv 2020. medRxiv:2020.04.18.20064774. [CrossRef]

6. Bruinen de Bruin, Y.; Lequarre, A.S.; McCourt, J.; Clevestig, P.; Pigazzani, F.; Zare Jeddi, M.; Colosio, C.; Goulart, M. Initial Impacts of Global Risk Mitigation Measures Taken during the Combatting of the COVID-19 Pandemic. Saf. Sci. 2020, 128, 104773. [CrossRef]

7. Talidong, K.J.B.; Toquero, C.M.D. Philippine Teachers' Practices to Deal with Anxiety amid COVID-19. J. Loss Trauma 2020, 1-7. [CrossRef]

8. BBC. Coronavirus: Only Go to Your Job If You Cannot Work from Home-Hancock. In Coronavirus Pandemic; BBC: London, UK, 2020.

9. Aguliera, E.; Nightengale-Lee, B. Emergency Remote Teaching across Urban and Rural Contexts: Perspectives on Educational Equity. Inf. Learn. Sci. 2020, 121, 471-478. [CrossRef]

10. Roy, D.; Tripathy, S.; Kar, S.K.; Sharma, N.; Verma, S.K.; Kaushal, V. Study of Knowledge, Attitude, Anxiety \& Perceived Mental Healthcare Need in Indian Population during COVID-19 Pandemic. Asian J. Psychiatr. 2020, 51, 102083. [CrossRef]

11. Tricco, A.C.; Langlois, E.; Straus, S.E. Rapid Reviews to Strengthen Health Policy and Systems: A Practical Guide; World Health Organization, Alliance for Health Policy and Systems Research: Geneva, Switzerland, 2017. [CrossRef]

12. Harari, M.B.; Parola, H.R.; Hartwell, C.J.; Riegelman, A. Literature Searches in Systematic Reviews and Meta-Analyses: A Review, Evaluation, and Recommendations. J. Vocat. Behavior. 2020, 118, 103377. [CrossRef]

13. Li, W.; Liao, J.; Li, Q.; Baskota, M.; Wang, X.; Tang, Y.; Zhou, Q.; Wang, X.; Luo, X.; Ma, Y.; et al. Public Health Education for Parents during the Outbreak of COVID-19: A Rapid Review. Ann. Transl. Med. 2020, 8, 628. [CrossRef]

14. Rodríguez-Hernández, C.F.; Cascallar, E.; Kyndt, E. Socio-Economic Status and Academic Performance in Higher Education: A Systematic Review. Educ. Res. Rev. 2020, 29, 100305. [CrossRef]

15. Khan, M.; Hassan, A.; Tarbert, H.; Harrison, C. CSR Reporting: A Review of Research and Agenda for Future Research. Management Research Review. 2020, 43, 1395-1419. [CrossRef]

16. Plöckinger, M.; Aschauer, E.; Hiebl, M.R.W.; Rohatschek, R. The Influence of Individual Executives on Corporate Financial Reporting: A Review and Outlook from the Perspective of Upper Echelons Theory. J. Account. Lit. 2016, 37, 55-75. [CrossRef]

17. Finfgeld-Connett, D.; Johnson, E.D. Literature Search Strategies for Conducting Knowledge-Building and Theory-Generating Qualitative Systematic Reviews. J. Adv. Nurs. 2013, 69, 194-204. [CrossRef]

18. Akçayır, M.; Akçayır, G. Advantages and Challenges Associated with Augmented Reality for Education: A Systematic Review of the Literature. Educ. Res. Rev. 2017, 20,1-11. [CrossRef] 
19. Lai, M.L.; Tsai, M.J.; Yang, F.Y.; Hsu, C.Y.; Liu, T.C.; Lee, S.W.Y.; Lee, M.H.; Chiou, G.L.; Liang, J.C.; Tsai, C.C. A Review of Using Eye-Tracking Technology in Exploring Learning from 2000 to 2012. Educ. Res. Rev. 2013, 10, 90-115. [CrossRef]

20. Rodrigues, F.; Mogarro, M.J. Student Teachers' Professional Identity: A Review of Research Contributions. Educ. Res. Rev. 2019, 28, 100286. [CrossRef]

21. Mahood, Q.; Van Eerd, D.; Irvin, E. Searching for Grey Literature for Systematic Reviews: Challenges and Benefits. Res. Synth. Methods 2014, 5, 221-234. [CrossRef] [PubMed]

22. Armijo-Olivo, S.; Stiles, C.R.; Hagen, N.A.; Biondo, P.D.; Cummings, G.G. Assessment of Study Quality for Systematic Reviews: A Comparison of the Cochrane Collaboration Risk of Bias Tool and the Effective Public Health Practice Project Quality Assessment Tool: Methodological Research. J. Eval. Clin. Pract. 2012, 18, 12-18. [CrossRef] [PubMed]

23. Mateen, F.J.; Oh, J.; Tergas, A.I.; Bhayani, N.H.; Kamdar, B.B. Titles versus Titles and Abstracts for Initial Screening of Articles for Systematic Reviews. Clin. Epidemiol. 2013, 5, 89-95. [CrossRef] [PubMed]

24. Majanja, M.K. The Status of Electronic Teaching within South African LIS Education. Libr. Manag. 2020, 41, 317-337. [CrossRef]

25. Abdulrahim, H.; Mabrouk, F. COVID-19 and the Digital Transformation of Saudi Higher Education. Asian J. Distance Educ. 2020, 15, 291-306. Available online: https:/ / asianjde.org/ojs/index.php/AsianJDE/article/view/468 (accessed on 15 May 2021).

26. Rajhans, V.; Memon, U.; Patil, V.; Goyal, A. Impact of COVID-19 on Academic Activities and Way Forward in Indian Optometry. J. Optom. 2020, 13, 216-226. [CrossRef]

27. Skulmowski, A.; Rey, G.D. COVID-19 as an Accelerator for Digitalization at a German University: Establishing Hybrid Campuses in Times of Crisis. Hum. Behav. Emerg. Technol. 2020, 2, 212-216. [CrossRef]

28. Zainuddin, Z.; Perera, C.J.; Haruna, H.; Habiburrahim, H. Literacy in the New Norm: Stay-Home Game Plan for Parents. Inf. Learn. Sci. 2020, 121, 645-653. [CrossRef]

29. Jayathirtha, G.; Fields, D.; Kafai, Y.B.; Chipps, J. Supporting Making Online: The Role of Artifact, Teacher and Peer Interactions in Crafting Electronic Textiles. Inf. Learn. Sci. 2020, 121, 381-390. [CrossRef]

30. Martzoukou, K.; Fulton, C. A Study of Higher Education Students' Self-Perceived Digital Competences for Learning and Everyday Life Online Participation. J. Doc. 2020, 76, 1413-1458. [CrossRef]

31. Zhou, L.; Wu, S.; Zhou, M.; Li, F. 'School's Out, But Class' On', The Largest Online Education in the World Today: Taking China's Practical Exploration During The COVID-19 Epidemic Prevention and Control As an Example. Best Evid. Chin. Edu. 2020, 4, 501-519. [CrossRef]

32. Code, J.; Ralph, R.; Forde, K. Pandemic Designs for the Future: Perspectives of Technology Education Teachers during COVID-19. Inf. Learn. Sci. 2020, 121, 419-431. [CrossRef]

33. Demuyakor, J. Coronavirus (COVID-19) and Online Learning in Higher Institutions of Education: A Survey of the Perceptions of Ghanaian International Students in China. Online J. Commun. Media Technol. 2020, 10. [CrossRef]

34. Kim, Y.; Ekachai, D. “Gee.” Exploring the Effects of Different Online Syllabus Formats on Student Engagement and Course-Taking Intentions. Coll. Teach. 2020, 68. [CrossRef]

35. Almaiah, M.A.; Al-Khasawneh, A.; Althunibat, A. Exploring the Critical Challenges and Factors Influencing the E-Learning System Usage during COVID-19 Pandemic. Educ. Inf. Technol. 2020, 25, 5261-5280. [CrossRef]

36. Longhurst, G.J.; Stone, D.M.; Dulohery, K.; Scully, D.; Campbell, T.; Smith, C.F. Strength, Weakness, Opportunity, Threat (SWOT) Analysis of the Adaptations to Anatomical Education in the United Kingdom and Republic of Ireland in Response to the Covid-19 Pandemic. Anat. Sci. Educ. 2020, 13, 301-311. [CrossRef]

37. Mailizar; Almanthari, A.; Maulina, S.; Bruce, S. Secondary School Mathematics Teachers' Views on e-Learning Implementation Barriers during the COVID-19 Pandemic: The Case of Indonesia. Eurasia J. Math. Sci. Technol. Educ. 2020, 16. [CrossRef]

38. Itow, R.C. Fostering Valuable Learning Experiences by Transforming Current Teaching Practices: Practical Pedagogical Approaches from Online Practitioners. Inf. Learn. Sci. 2020, 121, 443-452. [CrossRef]

39. Kessler, A.; Barnes, S.; Rajagopal, K.; Rankin, J.; Pouchak, L.; Silis, M.; Esser, W. Saving a Semester of Learning: MIT's Emergency Transition to Online Instruction. Inf. Learn. Sci. 2020. [CrossRef]

40. Aguilar, S.J. A Research-Based Approach for Evaluating Resources for Transitioning to Teaching Online. Inf. Learn. Sci. 2020, 121, 301-310. [CrossRef]

41. Azorín, C. Beyond COVID-19 Supernova. Is Another Education Coming? J. Prof. Cap. Community 2020. [CrossRef]

42. Dhawan, S. Online Learning: A Panacea in the Time of COVID-19 Crisis. J. Educ. Technol. Syst. 2020, 49, 5-22. [CrossRef]

43. Bao, W. COVID-19 and Online Teaching in Higher Education: A Case Study of Peking University. Hum. Behav. Emerg. Technol. 2020, 113-115. [CrossRef]

44. Yen, T.T.F. The Performance of Online Teaching for Flipped Classroom Based on COVID-19 Aspect. Asian J. Educ. Soc. Studies 2020, 8, 57-64. [CrossRef]

45. Cao, W.; Fang, Z.; Hou, G.; Han, M.; Xu, X.; Dong, J.; Zheng, J. The Psychological Impact of the COVID-19 Epidemic on College Students in China. Psychiatry Res. 2020, 287, 112934. [CrossRef]

46. Watermeyer, R.; Crick, T.; Knight, C.; Goodall, J. COVID-19 and Digital Disruption in UK Universities: Afflictions and Affordances of Emergency Online Migration. High. Educ. 2020, 81, 623-641. [CrossRef] [PubMed]

47. Peterson, L.; Scharber, C.; Thuesen, A.; Baskin, K. A Rapid Response to COVID-19: One District's Pivot from Technology Integration to Distance Learning. Inf. Learn. Sci. 2020. [CrossRef]

48. Regehr, C.; Goel, V. Managing COVID-19 in a Large Urban Research-Intensive University. J. Loss Trauma 2020, 1-17. [CrossRef] 
49. Justis, N.; Litts, B.K.; Reina, L.; Rhodes, S. Cultivating Staff Culture Online: How Edith Bowen Laboratory School Responded to COVID-19. Inf. Learn. Sci. 2020. [CrossRef]

50. Krishnamurthy, S. The Future of Business Education: A Commentary in the Shadow of the Covid-19 Pandemic. J. Bus. Res. 2020, 117, 1-5. [CrossRef]

51. MacMahon, S.; Leggett, J.; Carroll, A. Promoting Individual and Group Regulation through Social Connection: Strategies for Remote Learning. Inf. Learn. Sci. 2020. [CrossRef]

52. Raaper, R.; Brown, C. The Covid-19 Pandemic and the Dissolution of the University Campus: Implications for Student Support Practice. J. Prof. Cap. Community 2020. [CrossRef]

53. Baloran, E.T. Knowledge, Attitudes, Anxiety, and Coping Strategies of Students during COVID-19 Pandemic. J. Loss Trauma 2020, 1-8. [CrossRef]

54. Carter, R.A.; Rice, M.; Yang, S.; Jackson, H.A. Self-Regulated Learning in Online Learning Environments: Strategies for Remote Learning Learning. Inf. Learn. Sci. 2020. [CrossRef]

55. Fulton, C. Collaborating in Online Teaching: Inviting e-Guests to Facilitate Learning in the Digital Environment. Inf. Learn. Sci. 2020. [CrossRef]

56. Greenhow, C.; Galvin, S. Teaching with Social Media: Evidence-Based Strategies for Making Remote Higher Education Less Remote. Inf. Learn. Sci. 2020. [CrossRef]

57. Hendal, B.A. Kuwait University Faculty's Use of Electronic Resources during the COVID-19 Pandemic. Digit. Libr. Perspect. 2020. [CrossRef]

58. Mehta, D.; Wang, X. COVID-19 and Digital Library Services-A Case Study of a University's Library. Digit. Libr. Perspect. 2020. [CrossRef]

59. Murillo, A.P.; Jones, K.M.L. A “Just-in-Time” Pragmatic Approach to Creating Quality Matters-Informed Online Courses. Inf. Learn. Sci. 2020. [CrossRef]

60. Tammaro, A.M.; Tammaro, A.M. COVID 19 and Libraries in Italy. Int. Inf. Libr. Rev. 2020, 1-5. [CrossRef]

61. Nepal, R.; Ann, M.R. From Theory to Practice of Promoting Student Engagement in Business and Law-Related Disciplines: The Case of Undergraduate Economics Education. Educ. Sci. 2020, 10, 205. [CrossRef] 